\title{
Do assembly rules for bird communities operate in small, fragmented woodlands in an agricultural landscape?
}

\author{
R. J. Pakeman ${ }^{1}$, S. A. Hinsley ${ }^{2}$ and P. E. Bellamy ${ }^{2}$ \\ ${ }^{1}$ Macaulay Land Use Research Institute, Craigiebuckler, Aberdeen, AB15 8QH, UK. \\ Fax:+44 (0) 1224 311556, E-mail:r.pakeman@mluri.sari.ac.uk \\ ${ }^{2}$ Centre for Ecology and Hydrology, Monks Wood, Abbots Ripton, Huntingdon, Cambridgeshire, \\ PE28 2LS, UK.
}

Keywords: Favoured state, Guild, Landscape Ecology, Null models, Species distribution.

\begin{abstract}
The favoured state approach sensu Fox (1987) was used to investigate the existence of assembly rules for woodland bird communities in an agricultural landscape. When birds were classified according to gross breeding habitat requirements, year-round resident, 'true' woodland species showed an excess of favoured states suggesting a possible assembly rule. There was weaker evidence for a similar assembly rule governed by foraging requirements. This pattern was shown for all woods together, and for most categories of woods, grouped according to size, shape or size and shape together. Summer migrants did not show such patterns, and their arrival appeared to mask any patterns established by year-round resident species. The statistical significance of the excess of favoured states was highest in 1990, when bird population densities were considerably higher than in 1991 and 1992. Interspecific competition appears to be a factor in structuring woodland bird communities within the area sampled. Some implications for the action of these assembly rules on the results of further habitat fragmentation are discussed.
\end{abstract}

\section{Introduction}

A wide range of possible mechanisms exist for determining the presence of species in communities. One potential mechanism put forward by Diamond (1975) was that communities represent structured subsets of the regional species pool and that competition for shared resources imposes the structure (e.g., Fox 1987, Fox and Brown 1993, Wilson and Roxburgh 1994). There is still considerable debate over the existence of these community 'assembly rules', much of it reviewed in the papers in Weiher and Keddy (1999). Despite this continuing debate, there does now appear to be some evidence that patterns do exist within communities of both animals (Kelt et al. 1995, Fox 1999) and plants (Wilson and Roxburgh 1994, Weiher et al. 1998).

In this paper, one of the main methods put forward, that of detecting 'favoured states' (Fox 1987), has been adopted to investigate the structuring of woodland bird communities. Specifically that means testing the rule that "there is a much higher probability that each species entering a community will be drawn from a different functional group, until each group is represented, before the cycle repeats" (Fox 1987). A more general statement of this hypothesis, "there is a statistical tendency for functional groups to be represented as equally as possible in communities", has also been put forward (Fox and Brown 1993). A favoured state is one where the numbers of species in each functional group differ by no more than one species. This corresponds to the Alpha guild of Wilson (1999) and the type 2 assembly rule of Belyea and Lancaster (1999).

Fox's (1987) favoured state assembly rule was tested with data from bird communities of discrete woodland patches in an arable landscape in Cambridgeshire and Lincolnshire, UK (c. $2000 \mathrm{~km}^{2}$ ). Previous studies of assembly rules in birds and mammals (Fox and Brown 1993, Kelt et al. 1995, Gotelli et al. 1997) were conducted at much larger spatial scales or across a range of different biomes, such that the area encompassed by the sites exceeded the geographic ranges of some of the individual species (Stone et al. 1996). In contrast, the sites providing the data for this study consisted of relatively homogeneous habitat patches, all of which were within the geographic range of the resident species. Also, many of the bird species within the region studied abandon their summer ter- 
ritories and habitats (in which they were sampled) and spend the winter elsewhere, either in different geographic areas or in different local habitats. Thus, any assembly rules must operate every year rather than on the slower time scale envisaged by Fox and Brown (1993). Thus, the context of this analysis is considerably different from that of previous studies, and offers potential new insights into employment of the assembly rule concept in the analysis of patterns of co-occurrence in animal communities.

\section{Materials and methods}

Study area

A total of 164 woods within Cambridgeshire and southern Lincolnshire in eastern England was surveyed over three years $(1990-1992)$. The area was c. $70 \mathrm{~km}$ from north to south, and $35 \mathrm{~km}$ from east to west, roughly centred on Monks Wood $\left(52^{\circ} 24^{\prime} \mathrm{N}, 0^{\circ} 14^{\prime} \mathrm{W}\right)$. The woods ranged in size from 0.02 to 30 ha and consisted of largely broad-leaved tree species, though a few contained areas of intermixed conifers and broad-leaves. The surrounding landscape was dominated by intensive arable farming, with little remaining semi-natural habitat.

\section{Bird census methodology}

The woods were surveyed in each of the three years to determine their annual complement of breeding species. The birds were censused using an intensive mapping technique based on the methodology of the British Trust for Ornithology's Common Bird Census (Marchant 1983). However, all woods were visited four times each year between the end of March and the beginning of August, and were searched systematically by walking a route designed to encounter every potential breeding territory. The census employed strict criteria to differentiate between breeding birds and transients. Only breeding birds are considered in this analysis. Details of the techniques used have been presented elsewhere (Hinsley et al. 1995).

\section{Data used in analysis}

In total 66 bird species were detected by the census method. However, some species were excluded from the analysis for several reasons. The census technique was deemed inadequate to census accurately nocturnal and crepuscular species (the owls). A number of species were excluded as they were associated with non-woodland features within the woods, e.g., water bodies, man-made structures or other vegetation types. Extremely rare species (one or two occurrence across all woods), species with unusual behaviour (cuckoo) and game birds (artificially stocked and fed) were also excluded.

\section{Method of detecting favoured states}

The species-based randomisation method adopted by Stone et al. (1996), which answers many of the statistical problems of earlier algorithms (Simberloff et al. 1999) was used. In producing the null model distribution, this method keeps the species-specific information on woodland occupancy but allocates species randomly to functional groups. This method of constructing the null hypothesis surmounts a previous methodological problem in which the null model is not strictly null with respect to competition (the 'Narcissus' effect). This is achieved in the model by keeping row and column constraints on species distribution in the randomisation (as suggested by Wilson 1995), rather than only the row constraints of Fox and Brown (1993). Thus the method is similar to that adopted by Wilson and Roxburgh (1994), though the mechanism of testing for significance is different.

This species-based randomisation method (Stone et al. 1996) also has the advantage of maintaining geographical distribution within the null model of species data, hence preventing the co-occurrence in the model of species that are normally geographically isolated, another problem of the Fox and Brown method (Stone et al. 1996). This is perhaps less necessary at the geographic scale of the data used here, as all the bird species in this dataset were distributed across the whole area, though this method does maintain information within the null model about woodland preferences. For example, some bird species are rarely found in small woods - Eurasian Treecreeper (Certhia familiaris), Marsh Tit (Parus palustris) and Long-tailed Tit (Aegithalos caudatus) (Hinsley et al. 1996a). The method has been shown to perform well in limiting both Type 1 and Type 2 errors, and has been put forward as the most appropriate current method for detecting patterns caused by species interactions where there are strong species-area effects (Gotelli 2000).

The number of favoured states was calculated from the initial classification of species (see below). The probability of this number of favoured states achieved by chance was calculated by comparison with 10000 Monte Carlo simulations with the random allocation of species to classes. This high number was possible as the programme took c. 10 seconds for this number of simulations. The probability was represented by the proportion of simulated distributions containing the same number or more favoured states than the actual classification.

\section{A priori 'guild' definition}

Four basic methods of assignment to guilds (functional groups) were used to test if the distribution pattern of birds across the 164 woods could be attributed to the 
Table 1. Groupings and classes of bird species used in the analysis.

\begin{tabular}{lll}
\hline Grouping & Class & Description \\
\hline A. Gross breeding habitat & 1 & Small hole/cavity nesters \\
requirements & 2 & Non-cavity nesters requiring trees \\
& 3 & Species requiring dense cover \\
& 4 & Ubiquitous \\
B. Main foraging substrate & 1 & Tree canopy and trunks \\
& 2 & Low bushes \\
& 3 & Woodland floor \\
& 4 & Large/medium species foraging outside woodland \\
& 5 & Small species foraging outside woodland \\
C. Main foraging habits - & 1 & Tree canopy and trunks \\
woodland birds only & 2 & Low bushes \\
& 3 & Woodland floor \\
D. Gross breeding habitat & 1 & Small hole/cavity nesters \\
requirements - woodland & 2 & Non-cavity nesters requiring trees \\
birds only & 3 & Species requiring dense cover \\
& 4 & Ubiquitous \\
\hline
\end{tabular}

action of assembly rules (Table 1). The groupings were based on either gross breeding habitat requirements or main foraging habits. In group A, gross habitat requirements, the categories were selected as essential habitat requirements for breeding to occur. Given that some species are generalists in a woodland context, the categories had to include "ubiquitous" as well as more specific elements. In group B, main foraging substrate, the categories were again selected as essential foraging requirements. The distinction between species that forage mainly within the woodland and those that forage elsewhere is fundamental to the species ecology and thus this group had to include a category for foraging outside of woodland. Having made this distinction, it became clear that the ecological requirements of these "outside" foragers were rather diverse and the separation by body size was used as an unambiguous means of reflecting this diversity whilst keeping the number of categories within bounds. Also, to limit the number of guilds, some were merged. For instance, trunk-feeding species were put into a larger class (tree canopy and trunks), as only two of this type of bird were common in the area. The distinction between "true" woodland birds and "all" birds (groups C and D) was made because the species most dependent on woodland were expected to be those most likely to interact/compete with each other.

Species were allocated to these classes according to known information about their foraging ecology and breeding behaviour (Table 2). This method corresponds to the $\alpha 2$ guild classification method of Wilson (1999).

\section{More detailed tests}

The structure of the dataset allowed more detailed analyses to be carried out. Summer migrants and year- round residents were tested together and separately (Table 2) to investigate if each wintering strategy influenced the assembly rules within woodland during the breeding season. Also, each of the three years of data was tested separately to identify differences or similarities between years that might influence the weight of the conclusions drawn from the analysis. It should be noted though that the bird assemblage recorded may not have been entirely independent between years due to the effects of site fidelity.

The data were also divided by the size or shape of the woodlands (Table 3). Woodland size may affect species richness and population sizes, and hence the strength of assembly rule operation may vary accordingly. Shape may also influence the balance between woodland edge species and those favouring the interior. The effect of habitat size on assembly rule significance was tested by splitting the woods into four size categories of roughly equal numbers. Woodland shape was also used to classify the dataset as shape appeared to be significant in models relating species occurrence to habitat parameters (Hinsley et al. 1996ab). The population size of many species appears to be related to the availability of woodland edge rather than area. Shape was defined by the ratio $(c)$ between the actual perimeter and the perimeter of a circular wood of equal area (a ratio that is scale independent). The effect of shape was tested by analysing the differences between woods with a large amount of edge for their area $(c$ $\geq 1.5$ ) and woods with a relatively small amount of edge $(c<1.5)$. The effect of size and shape taken together was also tested. The effect of perimeter length alone was also tested as a method of classification, but it did not reveal any further patterns of interest. 
Table 2. Species used in the analysis. Species are shown as resident (R) or migratory (M). The Groupings (A-D) and Classes refer to those described in Table 1. Species names according to the British Ornithologists' Union (2000).

\begin{tabular}{|c|c|c|c|c|c|c|}
\hline \multirow[t]{2}{*}{ Species } & & \multirow{2}{*}{$\begin{array}{c}\text { Resident/ } \\
\text { Migrant } \\
\text { R/M }\end{array}$} & \multicolumn{4}{|c|}{$\begin{array}{l}\text { Allocated classes used } \\
\text { in each analysis }\end{array}$} \\
\hline & & & A & B & $\mathrm{C}$ & $\mathrm{D}$ \\
\hline Eurasian Sparrowhawk & Accipiter nisus & $\mathrm{R}$ & 2 & 4 & & \\
\hline Common Kestrel & Falco tinnunculus & $\mathbf{R}$ & 2 & 4 & & \\
\hline Stock Pigeon & Columba oenas & $\mathrm{R}$ & 2 & 4 & & \\
\hline Common Wood Pigeon & Columba palumbus & $\mathbf{R}$ & 4 & 4 & & \\
\hline Eurasian Collared Dove & Streptopelia decaocto & $\mathrm{R}$ & 2 & 4 & & \\
\hline European Turtle Dove & Streptopelia turtur & M & 3 & 4 & & \\
\hline Green Woodpecker & Picus viridis & $\mathrm{R}$ & 1 & 4 & & \\
\hline Great Spotted Woodpecker & Dendrocopos major & $\mathbf{R}$ & 1 & 1 & 1 & 1 \\
\hline Winter Wren & Troglodytes troglodytes & $\mathbf{R}$ & 4 & 3 & 3 & 4 \\
\hline Hedge Accentor (Dunnock) & Prunella modularis & $\mathrm{R}$ & 3 & 3 & 3 & 3 \\
\hline European Robin & Erithacus rubecula & $\mathbf{R}$ & 4 & 3 & 3 & 4 \\
\hline Common Nightingale & Luscinia megarhynchos & M & 3 & 3 & 3 & 3 \\
\hline Common Blackbird & Turdus merula & $\mathbf{R}$ & 4 & 3 & 3 & 4 \\
\hline Song Thrush & Turdus philomelos & $\mathrm{R}$ & 4 & 3 & 3 & 4 \\
\hline Lesser Whitethroat & Sylvia curruca & M & 3 & 2 & 2 & 3 \\
\hline Common Whitethroat & Sylvia communis & M & 3 & 2 & 2 & 3 \\
\hline Garden warbler & Sylvia borin & M & 4 & 2 & 2 & 4 \\
\hline Blackcap & Sylvia atricapilla & M & 4 & 2 & 2 & 4 \\
\hline Common Chiffchaff & Phylloscopus collybita & M & 2 & 1 & 1 & 2 \\
\hline Willow Warbler & Phylloscopus trochilus & M & 3 & 2 & 2 & 3 \\
\hline Goldcrest & Regulus regulus & $\mathrm{R}$ & 2 & 1 & 1 & 2 \\
\hline Spotted Flycatcher & Muscicapa striata & M & 2 & 1 & 1 & 2 \\
\hline Long-tailed Tit & Aegithalos caudatus & $\mathrm{R}$ & 2 & 1 & 1 & 2 \\
\hline Marsh Tit & Parus palustris & $\mathrm{R}$ & 1 & 2 & 2 & 1 \\
\hline Willow Tit & Parus montanus & $\mathrm{R}$ & 1 & 2 & 2 & 1 \\
\hline Coal Tit & Parus ater & $\mathrm{R}$ & 1 & 1 & 1 & 1 \\
\hline Blue Tit & Parus caeruleus & $\mathrm{R}$ & 1 & 1 & 1 & 1 \\
\hline Great Tit & Parus major & $\mathbf{R}$ & 1 & 1 & 1 & 1 \\
\hline Eurasian Treecreeper & Certhia familiaris & $\mathrm{R}$ & 1 & 1 & 1 & 1 \\
\hline Jay & Garrulus glandarius & $\mathrm{R}$ & 2 & 3 & 3 & 2 \\
\hline Black-billed Magpie & Pica pica & $\mathbf{R}$ & 4 & 4 & & \\
\hline Jackdaw & Corvus monedula & $\mathrm{R}$ & 2 & 4 & & \\
\hline Rook & Corvus frugilegus & $\mathrm{R}$ & 2 & 4 & & \\
\hline Carrion Crow & Corvus corone corone & $\mathrm{R}$ & 2 & 4 & & \\
\hline Common Starling & Sturnus vulgaris & $\mathrm{R}$ & 1 & 5 & & \\
\hline Tree Sparrow & Passer montanus & $\mathrm{R}$ & 1 & 3 & 3 & 1 \\
\hline Chaffinch & Fringilla coelebs & $\mathrm{R}$ & 4 & 1 & 1 & 4 \\
\hline European Greenfinch & Carduelis chloris & $\mathrm{R}$ & 3 & 5 & & \\
\hline European Goldfinch & Carduelis carduelis & $\mathrm{R}$ & 3 & 5 & & \\
\hline Common Linnet & Carduelis cannabina & $\mathrm{R}$ & 3 & 5 & & \\
\hline Common Bullfinch & Pyrrhula pyrrhula & $\mathrm{R}$ & 3 & 5 & & \\
\hline Yellowhammer & Emberiza citrinella & $\mathbf{R}$ & 3 & 5 & & \\
\hline
\end{tabular}

Table 3. Size and shape categories of woodlands used in the analysis. The parameter $\mathrm{c}$ is the ratio between the actual perimeter of the wood and the perimeter of a circular wood of the same area.

\begin{tabular}{llccc}
\hline Division & Class & \multicolumn{3}{c}{ Number of woods in analysis } \\
& & 1990 & 1991 & 1992 \\
\hline Size & $0.02-0.29 \mathrm{ha}$ & 52 & 41 & 41 \\
& $0.30-0.66 \mathrm{ha}$ & 34 & 33 & 33 \\
& $0.67-1.99 \mathrm{ha}$ & 44 & 44 & 44 \\
& $2.03-29.9 \mathrm{ha}$ & 34 & 33 & 33 \\
Shape & & & & \\
& $\mathrm{c}<1.5$ & 101 & 96 & 95 \\
Size and shape & $\mathrm{c} \geq 1.5$ & 63 & 55 & 56 \\
& & & & \\
& $0.02-0.66 \mathrm{ha}, \mathrm{c}<1.5$ & 46 & 41 & 40 \\
& $0.02-0.66 \mathrm{ha}, \mathrm{c} \geq 1.5$ & 39 & 33 & 34 \\
& $0.67-29.9 \mathrm{ha}, \mathrm{c}<1.5$ & 55 & 55 & 55 \\
No division & $0.67-29.9 \mathrm{ha}, \mathrm{c} \geq 1.5$ & 24 & 22 & 22 \\
\hline
\end{tabular}




\section{Results}

All woods

Allocation of species into functional groups using groupings A (gross breeding habitat requirements), B (main foraging habits) and $\mathrm{C}$ (main foraging habits woodland birds only) did not yield significantly higher numbers of favoured states than expected (Table 4), except in 1990 where grouping $C$ was almost significant at $5 \%(\mathrm{p}=0.057)$. However, grouping $\mathrm{D}$ (gross breeding habitat requirements - woodland birds only) in all three years showed significantly higher numbers of favoured states in the distribution of the 16 resident species than expected $(\mathrm{p}=0.016$ in 1990, $\mathrm{p}=0.045$ in 1991 and $\mathrm{p}=$ 0.044 in 1992). This pattern was not observed in migrant species, or if both migrant and resident species were tested as one dataset.

The distribution of the number of favoured states produced by the Monte Carlo randomisation and the calculated number within the data of grouping D are shown in Fig. 1 for each year. The fraction of possible favoured states (produced randomly) in excess of that in the collected data was smallest in 1990 (Fig. 1a) compared to both 1991 and 1992 (Fig. 1b \& c).

\section{Effect of wood size}

The significantly higher number than expected of favoured states (an excess) using the resident species in grouping D was apparent at all sizes of wood, though only marginally so at the smallest wood size $(0.02-0.29 \mathrm{ha})$. However, it was difficult to produce more favoured states from the data in 1991 and 1992, as 30 out of 32 and 32 out of 34 occupied woods, respectively, contained birds in a favoured state. Thus, the occurrence of two woods only with an unfavourable state was enough to change the probability to non-significance at the 5\% level. There was also a lower likelihood of observing favoured states where woods were large and/or had a high species richness. However, it may be possible that too few woods were present in both the smallest and largest size classes to detect favoured states reliably. Occasional excesses of favoured states were apparent in the migratory species and there was some excess of favoured states using grouping $\mathrm{C}$ at the smaller wood sizes, though only in some years (especially 1990).

\section{Wood shape}

The excess of favoured states in resident species using grouping D was apparently unaffected by the shape of the woodlands (Table 5). The marginal excess of favoured
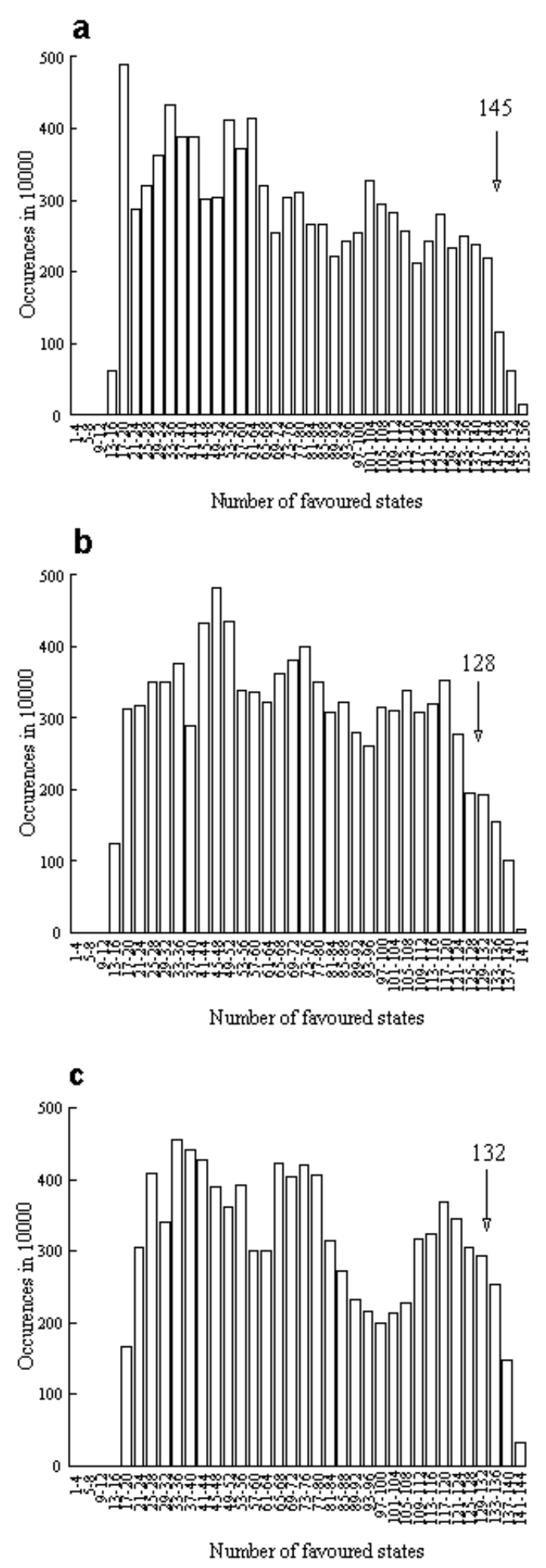

Figure 1. Distribution of calculated favoured states for all woods out of 10000 randomisations for 'true' woodland birds classified by gross breeding habitat requirements sampled in (a) 1990, (b) 1991 and (c) 1992. The number of favoured states shown by the collected data is indicated with an arrow. 
Table 4. The years $(90=1990,91=1991,92=1992)$ in which the presence of a statistically significant excess of favoured states was observed for all woodlands, and each class of woodland area. Bird species are grouped according to their habitat requirements or foraging habit (Table 1) and are classified according to their migratory status (Table 2). Probabilities are classified as: $* * *=p<0.001, * *=0.001 \geq p<0.01, *=0.01 \geq p<0.05, \uparrow=0.05 \geq p<0.1$.

\begin{tabular}{|c|c|c|c|c|c|c|c|c|c|c|c|c|c|c|c|c|c|}
\hline \multirow[t]{3}{*}{ Grouping } & \multirow{3}{*}{$\begin{array}{l}\text { Migratory } \\
\text { status (n) }\end{array}$} & \multirow{2}{*}{\multicolumn{4}{|c|}{$\begin{array}{c}\text { All } \\
\text { woods }\end{array}$}} & \multicolumn{6}{|c|}{ Size category (ha) } & \multirow{2}{*}{\multicolumn{3}{|c|}{$0.67-1.99$}} & \multirow{2}{*}{\multicolumn{3}{|c|}{$2.03-29.9$}} \\
\hline & & & & & & 0.0 & -0 & & & $0-0$ & & & & & & & \\
\hline & & Year & 90 & 91 & 92 & 90 & 91 & 92 & 90 & 91 & 92 & 90 & 91 & 92 & 90 & 91 & 92 \\
\hline \multirow[t]{3}{*}{ A } & All (42) & & - & - & - & - & - & - & - & - & $=$ & - & - & - & - & - & - \\
\hline & Resident (33) & & - & - & - & - & - & - & - & - & - & - & - & - & - & - & - \\
\hline & Migrant (9) & & - & - & - & - & - & - & - & - & - & - & - & - & - & - & - \\
\hline \multirow[t]{3}{*}{ B } & All (42) & & - & - & - & - & - & - & - & - & - & - & - & - & - & - & - \\
\hline & Resident (33) & & - & - & - & - & - & - & - & - & - & - & - & - & - & - & - \\
\hline & Migrant (9) & & - & - & - & - & - & - & - & - & - & - & - & - & - & - & - \\
\hline \multirow[t]{3}{*}{$\mathrm{C}$} & All (25) & & - & - & - & - & - & - & - & - & - & - & - & - & - & - & - \\
\hline & Resident (17) & & + & - & - & $* * *$ & - & - & - & - & + & $\dagger$ & *** & - & - & - & - \\
\hline & Migrant (8) & & - & - & - & - & - & - & - & - & - & - & - & - & - & - & - \\
\hline \multirow[t]{3}{*}{ D } & All (25) & & - & - & - & - & - & - & - & - & - & - & - & - & - & - & - \\
\hline & Resident (17) & & * & * & * & $* * *$ & $\dagger$ & $\dagger$ & * & *** & *** & * & * & $\dagger$ & * & + & $\dagger$ \\
\hline & Migrant (8) & & - & - & - & - & *** & - & - & - & - & - & * & - & - & - & - \\
\hline
\end{tabular}

Table 5. The years $(90=1990,91=1991,92=1992)$ in which the presence of a statistically significant excess of favoured states was observed for woodlands classified by size and shape, and by shape alone. Bird species are grouped according to their habitat requirements or foraging habit (Table 1) and are classified according to their migratory status (Table 2). Probabilities are classified as: $* * *=p<0.001, * *=0.001 \geq p<0.01, *=0.01 \geq p<0.05, \dagger=0.05 \geq p<0.1$.

\begin{tabular}{|c|c|c|c|c|c|c|c|c|c|c|c|c|c|c|c|c|c|c|c|c|}
\hline \multirow[t]{4}{*}{ Grouping } & \multirow{4}{*}{$\begin{array}{l}\text { Migratory } \\
\text { status (n) }\end{array}$} & \multicolumn{7}{|c|}{ Shape only } & \multicolumn{12}{|c|}{ Size (ha) and shape } \\
\hline & & \multirow{3}{*}{$\begin{array}{l}\text { Size } \\
\text { Shape } \\
\text { Year }\end{array}$} & \multirow{2}{*}{\multicolumn{3}{|c|}{$c<1.5$}} & \multirow{2}{*}{\multicolumn{3}{|c|}{$\mathrm{c} \geq 1.5$}} & \multicolumn{6}{|c|}{$0.02-0.66$} & \multicolumn{6}{|c|}{$0.67-29.9$} \\
\hline & & & & & & & & & \multicolumn{3}{|c|}{$c<1.5$} & \multicolumn{3}{|c|}{$\mathrm{c} \geq 1.5$} & \multicolumn{3}{|c|}{$\mathrm{c}<1.5$} & \multicolumn{3}{|c|}{$\mathrm{c} \geq 1.5$} \\
\hline & & & 90 & 91 & 92 & 90 & 91 & 92 & 90 & 91 & 92 & 90 & 91 & 92 & 90 & 91 & 92 & 90 & 91 & 92 \\
\hline \multirow[t]{3}{*}{$\bar{A}$} & All (42) & & - & - & - & - & - & - & - & - & - & - & - & - & - & - & - & - & - & - \\
\hline & Resident (33) & & - & - & - & - & - & - & - & - & - & - & - & - & - & - & - & - & - & - \\
\hline & Migrant (9) & & - & - & - & - & - & - & - & - & - & - & - & - & - & - & - & - & - & - \\
\hline \multirow[t]{3}{*}{ B } & All (42) & & - & - & - & - & - & - & - & - & - & - & - & - & - & - & - & - & - & - \\
\hline & Resident (33) & & - & - & - & - & - & - & - & - & - & - & - & - & - & - & - & - & - & - \\
\hline & Migrant (9) & & - & - & - & - & - & - & - & - & - & $\dagger$ & - & - & - & - & - & - & - & - \\
\hline \multirow[t]{3}{*}{$\mathrm{C}$} & All (25) & & - & - & - & - & - & - & - & - & - & - & - & - & - & - & - & - & - & - \\
\hline & Resident (17) & & $\dagger$ & - & - & $\dagger$ & $\dagger$ & - & $* * *$ & - & - & $* *$ & $\dagger$ & & $\dagger$ & - & - & $* * *$ & - & - \\
\hline & Migrant (8) & & - & - & - & - & - & - & - & - & - & - & - & - & - & - & - & - & - & - \\
\hline \multirow[t]{3}{*}{ D } & All (24) & & - & - & - & - & - & - & - & - & - & - & - & - & - & - & - & - & - & - \\
\hline & Resident (16) & & $*$ & * & $\dagger$ & * & $\dagger$ & * & $* * *$ & * & * & * & * & * & * & * & $\dagger$ & * & $\dagger$ & *** \\
\hline & Migrant (8) & & - & - & - & - & - & - & - & - & - & - & - & - & - & - & - & - & - & - \\
\hline
\end{tabular}

states using grouping $\mathrm{C}$ was also apparent in both shape classes.

\section{Shape/size classification}

As expected, this analysis yielded similar patterns of an excess of favoured state in the resident species using grouping D. More of the year/class combinations were significant at $5 \%$ compared to those using size alone. A small number of combinations of year and class also yielded excesses of favoured states with grouping $\mathrm{C}$.

\section{Discussion}

The null model approach

The null model construction approach put forward by Stone et al. (1996), and the distribution it produces after randomisation, appears to answer the criticisms of previous attempts to create appropriate null models for similar data (Gotelli and Graves 1996) and performs well for this type of data (Gotelli 2000). The following discussion can then focus on the biological assumptions and interpretation. 
Many non-statistical criticisms have been put forward against this type of approach. However, these do not apply as:

(1) The relatively small study area avoided problems arising from differences in species geographic ranges and in dispersal (common in studies of island bird faunas) (Wiens 1989).

(2) The relatively large sample size and consistent method of data collection.

(3) The study area was only recolonised by birds within the last 10-12,000 years (since the last Ice Age), assumptions about phylogenetic relationships or recently evolved species influencing distributions are not relevant (Wiens 1989, Gotelli and Graves 1996).

(4) Despite profound habitat changes as a result of agricultural improvement, the species pool in the study area is well established at both national and regional levels (Graves and Gotelli 1983, Wiens 1989).

(5) The guild classifications proposed are not taxonomically based (e.g., Diamond 1975), or based on hybrid structures of taxonomy and ecology (Fox and Brown 1993), but are defined solely on the ecological characteristic of the species involved. Some congeners (e.g., Turdus, Corvus) share the same guilds across all classifications whilst other genera have species in more than one class in a grouping (e.g., Parus, Phylloscopus).

\section{Community structure in small, fragmented woodlands}

In the simulations, species grouping D (gross breeding habitat requirements - woodland birds only) was consistently effective in producing a significant excess of favoured states for resident species. It appears that the occurrence of a species is dependent on competitive interactions for breeding habitat. Thus models based solely on habitat structure and composition may be improved in their predictive power if information on co-occurring species were included. The inclusion of all nesting birds (grouping A) failed to show any excess. There was also some evidence that structure was also a function of the foraging habits of woodland birds as grouping $\mathrm{C}$ showed a number of significant or near significant excesses of favoured states, particularly when populations were high (1990). Again the inclusion of all nesting birds (grouping B) failed to show any excess. It appears that the mainly larger birds (Columbidae, Accipitridae, Corvidae), as well as those feeding almost exclusively outside woodland (Table 2), present in groupings $\mathrm{A}$ and $\mathrm{B}$ but excluded from $\mathrm{C}$ and $\mathrm{D}$, are distributed independently of the structuring of the woodland bird species assemblage. Significance was similar across all shape and size combinations and classifications, though classifying woodland habitat in terms of shape did not appear to add any extra information to the groupings according to area alone.

A previous study using these data (Hinsley et al. 1996b) showed that individual species were not distributed randomly amongst the available habitats, but that some discrimination occurred. The results in this paper suggest that there were also interspecific effects influencing the distribution of species, and hence apparently structuring these woodland bird communities. These conclusions are counter to those drawn by Haila et al. (1993) in a smaller study who suggested that the location of breeding pairs varied randomly between years, and that species distribution was a result of random sampling from the local population.

\section{Ecological relevance}

The analysis indicates that an assembly rule may be functioning at relatively small scales as well as over large geographic scales (reviewed in Wiens 1989; Gotelli and Graves 1996). As the statistical patterns are repeated between years and the species turnover is relatively rapid (10 - 100\% of species per year - Hinsley et al. 1995), it appears that assembly rules are functioning at short time scales as well as at the longer time scales involved in the assembly of island bird faunas (Diamond 1975).

That resident, woodland species show the strongest interaction makes ecological sense given that niche overlap was likely to be most extensive in terms of both resources and time (i.e., winter and summer) for these species. It is interesting that for the smallest area classification $(0.02-0.29$ ha) only the 1990 data were significant at $5 \%$. There was considerable bird mortality in February 1991 (prior to 1991 census), both nationally (Marchant and Musty 1992) and locally (Bellamy et al. 1996) such that populations of many species were substantially lower in 1991 and 1992 than in 1990. Thus interspecific interactions (as well as intraspecific interactions - Hinsley et al. 1996b) may have decreased in importance at these lower population levels suggesting that assembly rules may only function at relatively high population levels. Conversely, in large woods the assembly rules may not operate at the level of the whole wood, but rather within smaller areas within the wood or else the assembly rule as identified by favoured states may breakdown at high species richness. More detailed territory mapping would be necessary to detect the operation of assembly rules under these circumstances.

The apparent operation of assembly rules concerning resident species is not mirrored in the distribution of mi- 
grant species (though a small number of significant relationships do appear in the smallest woodland area classes) or of all the species taken together. The presence of the migrants coincides with the period of maximum resource availability in the woodlands and thus their distribution may simply be superimposed upon the structure established by the residents (Timonen et al. 1994). This counters the proposition that the strongest interactions are over breeding/nesting requirements rather than over foraging requirements. The simultaneous arrival of a large number of migrants may facilitate such a process by swamping the defences of resident territory holders, but there is little evidence for such an effect. When numbers of resident breeders are low, migrants may fill up gaps in the resident community, giving rise to the appearance of structure in the migrants also. Such an outcome would be most likely when numbers of arriving migrants were also relatively low, as in 1991 (due to poor weather conditions during spring migration) when evidence of structure was detected for migrants in grouping D in some woodland size categories (Table 4). Although competition would be expected to be lower when numbers were low, the appearance of structuring could be due largely to interactions with resident species.

An important consequence of the operation of assembly rules arises if their action results in non-linear changes in population size as the area of habitat changes. As suitable habitat becomes increasingly fragmented or restricted in area, or conversely if habitat area increased and fragmentation decreased, changes in the population of a single species as habitat availability changes may not scale linearly from current distribution patterns (Hinsley et al. 1996b).

This study demonstrates that at least part of the bird communities in small, fragmented woodlands in a largely agricultural landscape are structured by an assembly rule. This differs from many previous demonstrations of assembly rules in that the geographic scale is smaller, the methodology has been improved (Stone et al. 1996), the species are mobile and assembly happens over short time scales. The implications of this may be considerable. Predictive models in landscape ecology are currently based on the relationship between individual species and habitat and occasionally with predators or food sources. The interactions between species within the same guild means that species are not distributed randomly within a habitat and that greater explanatory power may be gained by the simultaneous consideration of similar species. For species conservation, the employment of landscape ecological models without information on competing species may result in poor decision making. Acceptance of the opera- tion of assembly rules means that consideration then has to be given to methods of including many species in models together and in developing methods of analysing less well structured data, as studies of the type used here are uncommon.

Acknowledgements: We would like to thank all the landowners, managers, farmers and game keepers who kindly allowed us to work on their land. Thanks are also due to Cambridgeshire County Council, English Nature and The Wildlife Trust for access. The work was part funded the NERC Joint Agriculture and the Environment Programme (JAEP).

\section{References}

Bellamy, P.E., S. A.Hinsley and I. Newton. 1996. Local extinctions and recolonisations of passerine bird populations in small woods. Oecologia 108:64-71.

Belyea, L.R. and J. Lancaster. 1999. Assembly rules within a contingent ecology. Oikos 86:402-416

British Ornithologists' Union. 2000. The British List, $3^{\text {rd }}$ edition. Tring, UK.

Diamond, J.M. 1975. Assembly of species communities. In: M.L. Cody and J. M. Diamond (eds), Ecology and Evolution of Communities. Harvard University Press, Cambridge MA., pp. 342444.

Fox, B.J. 1987. Species assembly and the evolution of community structure. Evolutionary Ecology 1:201-213.

Fox, B.J. 1999. Genesis of an assembly rule. In: E. Weiher and P.A. Keddy (eds), Ecological Assembly Rules. Perspectives, Advances, Retreats. Cambridge University Press, Cambridge, pp. 23-57.

Fox, B.J. and J. H. Brown. 1993. Assembly rules for functional groups in North American desert rodent communities. Oikos 67:358-370.

Gotelli, N.J. 2000. Null model analysis of species co-occurrence patterns. Ecology 81:2606-2621.

Gotelli, N.J. and G.R. Graves. 1996. Null Models in Ecology. Smithsonian Institution Press, Washington.

Gotelli, N.J., N.J. Buckley. and J.A. Wiens. 1997. Co-occurrence of Australian land birds: Diamond's assembly rules revisited Oikos 80:311-324.

Graves, G.R. and N.J. Gotelli. 1983. Neotropical land-bridge avifaunas: new appraoches to null hypotheses in biogeography. Oikos 41:322-333.

Haila, Y., I.K. Hanski and S. Raivio. 1993. Turnover of breeding birds in small forest fragments: the "sampling" colonization hypothesis corroborated. Ecology 74:714-725.

Hinsley, S.A., P.E. Bellamy and I. Newton. 1995. Bird species turnover and stochastic extinction in woodland fragments. Ecography 18:41-50.

Hinsley, S.A., P.E. Bellamy, I. Newton, I. and T. H. Sparks. 1996a. Influences of population size and woodland area on bird species distributions in small woods. Oecologia 105:100-106.

Hinsley, S.A., R.J. Pakeman, P.E. Bellamy and I. Newton. 1996b. Influences of habitat fragmentation on bird species distributions and regional population sizes. Proceedings of the Royal Society of London, B. 263:307-313.

Kelt, D.A., M.L. Taper and P.L. Meserve. 1995. Assessing the impact of competition on community assembly: a case study using small mammals. Ecology 76:1283-1296. 
Marchant, J. 1983. BTO Common Bird Census Instructions. British Trust for Ornithology, Tring, Hertfordshire.

Marchant, J. and L. Musty. 1992. Common bird census 1990-91 index report. British Trust for Ornithology News 182:9-12.

Simberloff, D., L. Stone and T. Dayan. 1999. Ruling out a community assembly rule: the method of favored states. In: E. Weiher and P.A. Keddy (eds), Ecological Assembly Rules. Perspectives, Advances, Retreats. Cambridge University Press, Cambridge, pp.58-74.

Stone, L., T. Dayan and D. Simberloff. 1996. Community-wide assembly patterns unmasked: the importance of species' differing geographic ranges. The American Naturalist 148:997-1015.

Timonen, S., M. Mönkkönen and M. Orell. 1994. Does competition with residents affect the distribution of migrant territories? Ornis Fennica 71:55-60.

Weiher, E. and P. A. Keddy. 1999. Ecological Assembly Rules. Perspectives, Advances, Retreats. Cambridge University Press, Cambridge.
Weiher, E., G.D.P. Clarke and P.A. Keddy. 1998. Community assembly rules, morphological dispersion, and the coexistence of plant species. Oikos 81: 309-322.

Wiens, J.A. 1989. The Ecology of Bird Communities. Volume 1. Foundations and Pattern. Cambridge University Press, Cambridge.

Wilson, J.B. 1995. Null models for assembly rules: the Jack Horner effect is more insidious than the Narcissus effect. Oikos 72:139144.

Wilson, J.B. 1999. Guilds, functional types and ecological groups. Oikos 86:507-522.

Wilson, J.B. and S. H. Roxburgh. 1994. A demonstration of guildbased assembly rules for a plant community, and determination of intrinsic guilds. Oikos 69:267-276. 